\title{
Autogenous Tooth Bone, its Theoretical Background and Practice in Clinical Dentistry
}

\section{Jeong Keun Lee}

Department of Dentistry, Ajou University School of Medicine, Woncheon-dong, Yeongtong-gu, Suwon-si, Gyeonggi-do, South Korea

"Corresponding author: Jeong Keun Lee, Professor, Department of Dentistry, Ajou University School of Medicine, Woncheon-dong, Yeongtong-gu, Suwon-si, Gyeonggi-do, South Korea, Tel: +82 31219 5333; Fax: +82 31219 5329; E-mail: arcady@ajou.ac.kr

Received date: March 23, 2014, Accepted date: December 31, 2014, Published date: January 3, 2015

Copyright: $\odot 2015$ Jeong KL et al. This is an open-access article distributed under the terms of the Creative Commons Attribution License, which permits unrestricted use, distribution, and reproduction in any medium, provided the original author and source are credited.

\section{Short Communication}

Since the emergence of the term "bone formation by autoinduction" on the 3698th issue of the Science published on Nov 121965 [1], we are accustomed to "osteoinduction" after Urist who coined this term. As early as in 1967, Dr. Yeomans, who was in the same academic group with Dr. Urist, published an article on the same effect by decalcified tooth [4]. This study preceded 43 years to the first article that insisted on the usefulness of autogenous human tooth as a bone graft materials [3]. I'm introducing this "Autogenous bone derived from tooth (AutoBT)" with some background articles and my clinical experience.

Bone graft material derived from autogenous human tooth is without strict regulation governing the production and marketing of the synthetic bone graft materials because it is a kind of autogenous material. AutoBT was government-approved as a "New Excellent Technology" by the Ministry of Health and Welfare in 2012 [4], which means Korean government appreciated the value of the autogenous tooth bone in the viewpoint of technology as well as in the viewpoint of health and welfare. And I myself addressed the 21th International Conference on Oral and Maxillofacial Surgery on the autogenous tooth bone [5].

Inorganic component of this material was fully analyzed using SEM, energy dispersive X-ray spectroscopy (EDS), and X-ray diffraction (XRD) analysis [6]. In this in vitro study, different region of the human tooth showed different measure in the $\mathrm{Ca} / \mathrm{P}$ ratio, and that of dentin compares to human bone which is composed of low-crystalline hydroxyapatite structure. As we know, materials change their character from low to high crystal structure with heating. Because of the nature of low crystallinity of hydroxyapatite structure of teeth, heating is not recommended in the production of autogenous tooth bone. Another reason for no heat treatment is the preservation of the organic component residing in the teeth. Autogenous material causes no immunogenicity and don't need to be removed. Moreover, remaining organic components contains BMPs which functions as a potent skeletal mesoderm inducer, harbouring osteoinduction capacity to this material.

Animal study using miniature pigs confirmed good results with this tooth-derived bone graft material in histomorphometric analysis $[7,8]$. We compared the new bone formation of the autogenous tooth bone with that of synthetic hydroxyapatite. Twelve-week specimens from maxillary sinus graft and 4-week specimens from established mandibular defects filling were prepared and evaluated. Twelve week means 1 sigma $(\sigma)$ period of bone remodeling, for the $\sigma$ period for pigs and dogs are known to be 12 weeks [9]. Especially we observed new bone formation encroaching the graft material in the 12-week specimen (Figure 1).

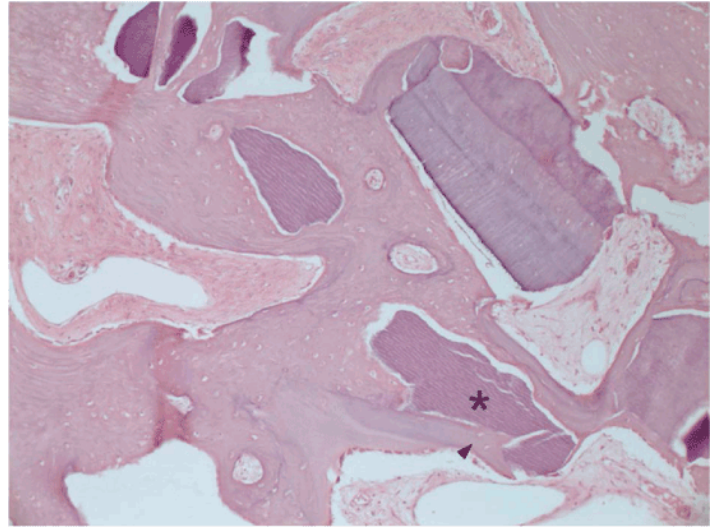

Figure 1: 12 week specimen of the autogenous pig tooth at magnification of $\times 100$ ( $\mathrm{H} \& \mathrm{E}$ staining). New bone (arrowhead) is encroaching into the existing graft material of autogenous pig tooth origin (asterisk) showing the evidence of bone remodeling. Courtesy by Lee ( J Kor Assoc Oral Maxillofac Surg 39:120-126).

It was evident that graft AutoBT materials were slowly replaced by new bone, participating in bone remodeling process. Both group showed new bone formation, but semi-quantitative study using histomorphometric analysis showed high rate of new bone formation in the AutoBT group.

My clinical experience with autogenous tooth bone is as follows. We have 46 patients (79 cases) of AutoBT between April 2010 and February 2013. Sixty six cases related with dental implant were selectively included in our study. Implant stability quotient (ISQ) was evaluated clinically, and bone resorption was evaluated radiologically after 9 months of occlusal loading. ISQ showed increasing tendency through the loading period (67 to 76 to 78 ) and average bone loss after bone graft was $0.3 \mathrm{~mm}$ in GBR group and $0.7 \mathrm{~mm}$ in sinus graft group [10]. One of these clinical cases is presented in Figure 2 from the preoperative to full functional stage (Confer to the legend of the figure for detailed information). Data on the AutoBT are accumulating which will enlarge the database to evaluate this material. Personal opinion with this material in our clinic is considerably positive, for there is no case of graft failure except minor complication such as small denudation which heals well after careful dressing. 
Citation: Jeong Keun Lee (2015) Autogenous Tooth Bone, its Theoretical Background and Practice in Clinical Dentistry. Anaplastology 4: 143. doi:10.4172/2161-1173.1000143

Page 2 of 2

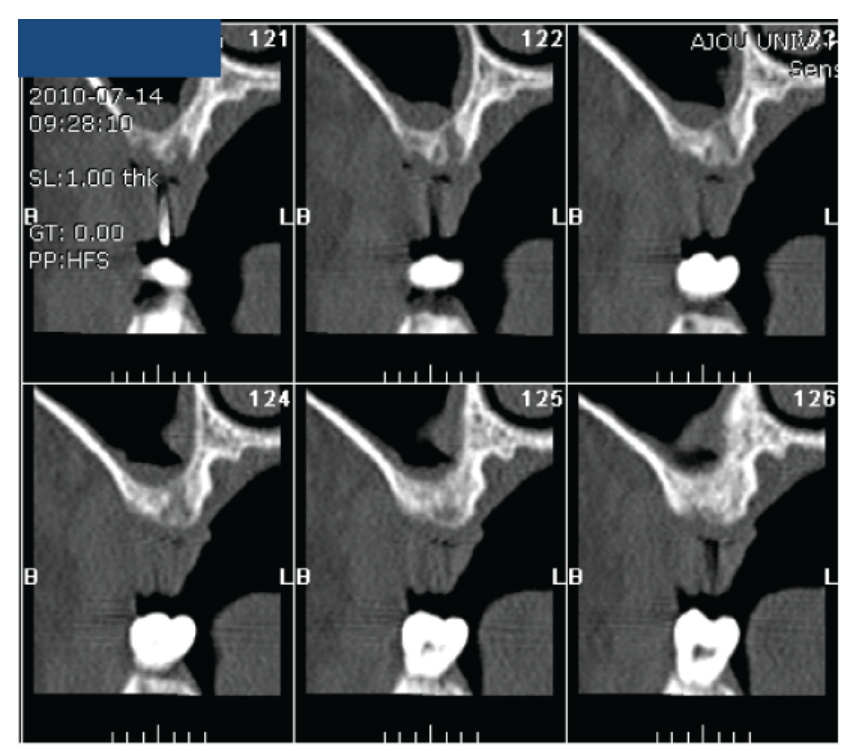

Figure 2 (a): Coronal section of CT scan of the patient who needs sinus floor augmentation for dental implant installation on the maxillary alveolar ridge.

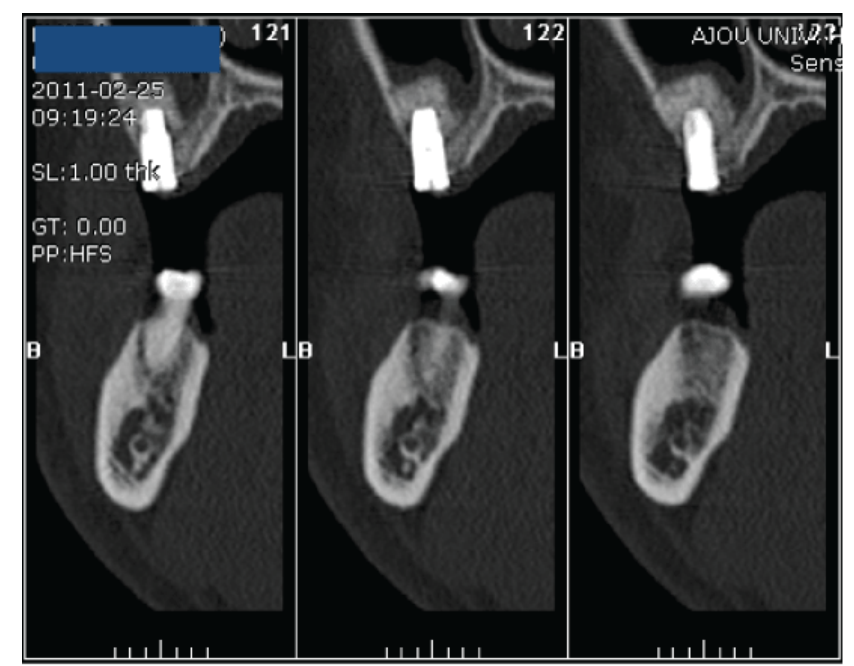

Figure 2 (b): 7 months after the sinus floor augmentation simultaneous with dental implant installation. Radiopaque collection is engaged around the installed dental implant which shows consollidation of the autogenous tooth bone graft.

Considering the result of the in vitro study, in vivo study using miniature pigs and my clinical experience with this material, I conclusively remark that dentists are empowered to enlarge the realm of the "autogenous" graft with this autogenous bone graft material derived from human tooth.

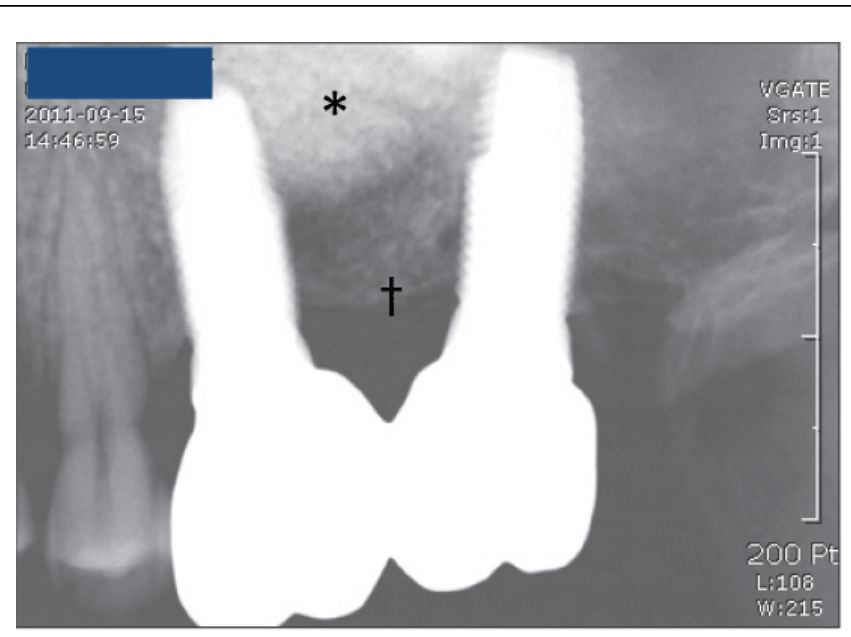

Figure 2 (c): 14 months after the initial tooth bone graft when active occlusal loading has been provided since sperstructure delivery 6 month before. Graft site is the hyper-radiopaque area (asterisk) which shows continuous trabecular pattern from the peripheral recipient site (dagger). This continuous trabecular bone pattern means adequate bone remodeling showing capacity of the autogenous tooth bone as an optimal scaffold material.

\section{References}

1. Urist MR (1965) Bone: formation by autoinduction. Science 150: 893-899.

2. Yeomans JD, Urist MR (1967) Bone induction by decalcified dentine implanted into oral, osseous and muscle tissues. Arch Oral Biol 12: 999-1008.

3. Kim YK, Kim SG, Byeon JH, Lee HJ, Um IU, et al. (2010) Development of a novel bone grafting material using autogenous teeth. Oral Surg Oral Med Oral Pathol Oral Radiol Endod 109: 496-503.

4. http://www.khidi.or.kr/www/run.do?

menu=01010000\&bbs_cd=NOTICE\&act=view\&article_sid $=7267$.

5. Lee JK (2013) Autogenous tooth bone, its theoretical background and practice in clinical dentistry. Proceedings of the International Conference on Oral and Maxillofacial Surgery.

6. Kim YK, Kim SG, Oh JS, Jin SC, Son JS, et al. (2011) Analysis of the inorganic component of autogenous tooth bone graft material. J Nanosci Nanotechnol 11: 7442-7445.

7. Jeong HR, Hwang JH, Lee JK (2011) Effectiveness of autogenous tooth bone used as a graft material for regeneration of bone in miniature pig. J Korean Assoc Oral Maxillofac Surg. 37:375-379.

8. Lee du H, Yang KY, Lee JK (2013) Porcine study on the efficacy of autogenous tooth bone in the maxillary sinus. J Korean Assoc Oral Maxillofac Surg 39: 120-126.

9. Doll B et al (2008) Overview of fracture repair: Pietrzak WS (editor) Musculoskeletal tissue regeneration: biological materials and methods. Humana Press, New Jersey.

10. Han MW, Lee JK (2013) Clinical study on the effect of the autogenous tooth bone graft material (AutoBT). J Korean Assoc Maxillofac Plast Reconstr Surg. 35:221-226. 